\title{
Excitator Germaniae. La recepción de Miguel de Unamuno en la República de Weimar
}

\author{
Excitator Germaniae. The Reception of Miguel \\ de Unamuno in the Republic of Weimar
}

\author{
Mario Martín Gijón \\ Universidad de Extremadura \\ marting@unex.es \\ ORCID iD: http://orcid.org/0000-0002-4155-1509
}

\section{RESUMEN}

La recepción de Unamuno en Alemania apenas ha sido estudiada. Sin embargo, entre 1924 y 1933, fue uno de los escritores extranjeros que más atención suscitó en este país. Este artículo, basado en el análisis de casi un centenar de publicaciones alemanas, estudia su recepción tanto en la prensa diaria como en todo tipo de revistas, especialmente literarias.

Palabras Clave: recepción; Alemania; República de Weimar; Unamuno.

\section{ABSTRACT}

Unamuno's reception in Germany has barely been studied, although, between 1924 and 1933, he was one of the most popular foreign writers in this country. This essay, based in the analysis of almost hundred German publications, studies his reception as well in the daily press as in all kinds of journals, especially literary ones.

Key words: Reception; Germany; Weimar Republic; Unamuno.

1. INTRODUCCIÓN. LAS PRIMERAS «OBRAS COMPLETAS» DE Miguel DE UNAMUNO

En pocos países fue tan influyente la obra de Miguel de Unamuno como en la Alemania de los años anteriores a la llegada del régimen nazi, que pondría fin a una de las épocas más brillantes de la cultura alemana. Por citar dos ejemplos bien dispares, en sus memorias, Ludwig Marcuse recordaría el efecto que, siendo estudiante de filosofía, le causó Del sentimiento trágico de la vida 
(1981: 224-227) y Gerhart Hauptmann reflexionaría, impresionado, en sus diarios de 1932 sobre la idea unamuniana de que los personajes de un escritor son más reales que este, para preguntarse entonces si debía reconocerse a través de la ficción (1980: 172-175). Como veremos, el nombre de Unamuno aparecería en cualquier publicación cultural editada en el ámbito germanófono entre 1924 y 1933, coincidiendo con el destierro y regreso de Unamuno y la edición en Alemania de sus «obras reunidas», una iniciativa única en cualquier otra lengua extranjera. Sin embargo, los estudios sobre la relación entre Unamuno y Alemania son relativamente escasos, a pesar de que ya en 1964, con motivo del centenario de su nacimiento, el hispanista Franz Niedermayer dedicara un estudio en el que, aunque apuntaba algunas informaciones sobre la recepción de Unamuno, básicamente se centraba en las fuentes alemanas de sus obras. La edición de la correspondencia entre Unamuno y sus corresponsales alemanes supuso un notable avance en este aspecto pero, como reconocían sus editores, Pedro Ribas y Fernando Hermida, quedaba mucho por investigar en torno a «la relación entre la recepción de Unamuno y la república de Weimar», analizando especialmente «las recensiones que salieron, los artículos que sobre él se escribieron en distintas revistas, así como qué grupos fueron los que se interesaron por su obra» (2002: 11-12).

Poco antes de esta edición, había aparecido un valioso artículo de Shirley King, donde la profesora norteamericana recorría sucintamente la época de mayor celebridad de Unamuno en Alemania, basándose en los recortes de prensa alemana archivados en la Casa-Museo Miguel de Unamuno de Salamanca, y donde llegaba a algunas conclusiones que hay que tener en cuenta. La primera fue establecer la relación directa entre el destierro de Unamuno y su celebridad en Alemania, de modo que «the exile was the cause of his sudden recognition in Germany» (King, 2000: 291). Tras repasar las reseñas que Unamuno recibió en una serie de publicaciones, tanto diarios como revistas de diversa índole, Shirley King llega a la conclusión de que «there was no critical consensus on whether Miguel de Unamuno was a religious, a literary, or a political figure. In spite of the translation and distribution of a major component of his literary work, his fame was short-lived and primarily sensational in nature, from his exile in 1924 to his return in Spain in 1930» (2000: 305). Con ello llega a una conclusión negativa similar a la de Franz Niedermayer, para quien «la recepción de Unamuno por parte de los alemanes es la historia de un malentendido, donde la política fue tomada por filosofía» (1964: 193) $)^{1}$. Sin embargo, después de un exhaustivo estudio, no solo de las críticas archivadas en la Casa-Museo Miguel de Unamuno, sino de todo tipo de publicaciones periódicas en diversas bibliotecas y hemerotecas alemanas, resulta un panorama

\footnotetext{
${ }^{1}$ La traducción, al igual que la del resto de citas de obras en lengua alemana, es mía.
} 
en el que se aprecia una recepción mucho más amplia, compleja e interesante de la conocida hasta ahora ${ }^{2}$.

Los resultados serán presentados, para mayor claridad, según la índole de las publicaciones que atendieron a la obra de Unamuno, recorriendo la prensa periódica, las revistas literarias y culturales, las publicaciones filosóficas y religiosas, y finalmente otro tipo de publicaciones, de ocio, para mujeres e incluso del ámbito médico. Siguiendo el concepto de campo literario acuñado por Pierre Bourdieu (1992) como espacio de producción del valor de las obras, indagaremos sobre los usos concretos que se hizo de Unamuno y su obra, desde los distintos grupos del complejo campo literario de la República de Weimar. Pero para ello es preciso comenzar destacando brevemente los principales hitos de la traducción de las «obras reunidas» publicadas en Múnich por la editorial Meyer \& Jessen, dirigida por Heinrich Auerbach, y que hicieron posible la amplia difusión de Unamuno en Alemania.

Los tres primeros volúmenes de las obras reunidas se publicaron en 1925. El primer volumen era Del sentimiento trágico de la vida [Das tragische Lebensgefühl] (Unamuno, 1925b), traducida por Paul Adler, que firmó con el seudónimo de Robert Friese, y con un prólogo de Ernst Robert Curtius, que reproducía el importante artículo que según veremos, había publicado en el Neue Zürcher Zeitung. El segundo volumen contenía la traducción de Abel Sánchez [Abel Sanchez. Die Geschichte einer Leidenschaft] (Unamuno, 1925c), realizada por el romanista suizo Walther von Wartburg, quien ya en 1920 había escrito a Unamuno pidiéndole permiso para «traducir al alemán algunos de sus escritos» (Ribas y Hermida, 2002: 213) y que unos meses después tradujera la novela en cuestión. Tras un contencioso entre Von Wartburg y el editor Heinrich Auerbach (Unamuno, 2012: 95)3 , finalmente este aceptaría publicar la traducción ya existente de Von Wartburg, aunque se tomaría la libertad de abreviar arbitrariamente el prólogo escrito por el traductor y suprimir su nombre, vengándose de este modo poco honorable por las disputas sobre los derechos de las obras de Unamuno (Ribas y Hermida, 2002: 336-342). El romanista suizo opinaba que era en esta novela donde se expresaba más nítidamente la disposición espiritual de Unamuno, y elogiaba la tensión dramática de los diálogos (Unamuno, 1925c: 5-6). El tercer volumen [Der Spiegel des Todes. Novellen] (Unamuno, 1925d), contenía la traducción de las Tres novelas ejem-

${ }^{2}$ Este estudio pudo realizarse gracias a una estancia de investigación de tres meses en Alemania, apoyada por el DAAD (Deutscher Akademischer Austauschdienst / Servicio Alemán de Intercambio Académico). Especialmente útiles me fueron los fondos de la Biblioteca Universitaria de Fráncfort del Meno.

${ }^{3}$ En la reciente (y por otra parte excelente) edición de las Cartas del destierro de Miguel de Unamuno, sus editores confunden a Heinrich Auerbach con el célebre romanista Erich Auerbach (Unamuno, 2012: 339), aunque aquel ya había sido identificado correctamente por Ribas y Hermida (2002: 352). 
plares y un prólogo, junto con la selección de cuentos de El espejo de la muerte, que daba título al volumen. Este volumen tenía la peculiaridad que, mientras las Tres novelas ejemplares y un prólogo habían sido traducidas por Otto Buek, los cuentos de El espejo de la muerte fueron traducidos por Oswald Jahns.

A partir de ese año, el frenético ritmo de las obras reunidas se ralentizaría. El año 1926 vio la publicación de La vida de Don Quijote y Sancho [Das Leben Don Quijotes und Sanchos] (Unamuno, 1926 a y b) que ocupó los volúmenes cuarto y quinto de las obras reunidas. Excepcionalmente, el traductor Otto Buek antepuso una breve introducción a esta obra, que no consideraba apropiado llamar un comentario, sino «una personalísima creación en la que narración y confesión se enlazan para formar un peculiar género poético sumamente atractivo» (Unamuno, 1926a: VIII).

Según habían acordado Unamuno y Buek (Ribas y Hermida, 2002: 108), al año siguiente apareció la traducción de Niebla [Nebel] (Unamuno, 1927c) como sexto volumen, y en 1928 saldrían los volúmenes séptimo y octavo, conteniendo La Tía Tula [Tante Tula] (Unamuno, 1928b) y La agonía del cristianismo [Die Agonie des Christentums] (Unamuno, 1928c), igualmente traducidas por Buek. Sin embargo, y aunque la idea inicial del editor Auerbach y Buek era publicar las obras completas de Unamuno, la situación económica hizo imposible proseguir la empresa, de modo que ya en 1929, será una asociación berlinesa de amigos de los libros la encargada de publicar Paz en la guerra (Unamuno, 1929), con un epílogo de Buek. Al año siguiente, la conocida editorial Reclam, de Leipzig, editaba un breve tomito con una selección de los cuentos aparecidos en el tercer volumen de las obras reunidas, traducidos por Otto Buek y Oswald Jahns (Unamuno, 1930).

La quiebra de la editorial Meyer \& Jessen en 1932 supuso el final del proyecto de las obras reunidas e influyó claramente en el declive del interés por Unamuno, en el que también tendrá que ver, como se puede imaginar, el forzado empobrecimiento del mundo literario bajo el régimen nazi. Aún en 1933, la Phaidon-Verlag de Viena, dirigida por Béla Horovitz, asumió los derechos de las obras ya traducidas, que reeditó en cuatro volúmenes (Unamuno, 1933), siguiendo su línea de ofrecer obras de calidad a precios populares. Sin embargo, la anexión de Austria a la Alemania nazi en 1938 obligaría al exilio a los editores, quedando de este modo definitivamente truncada la difusión de las obras de Unamuno.

2. Del «germanófobo de Salamanca» a las visitas a Unamuno. LA RECEPCIÓN EN LA PRENSA PERIÓDICA

A nivel periodístico según veremos, más que la obra de Unamuno, atraía la figura del exiliado político, del intelectual desterrado por sus insobornables 
convicciones. Ciertamente, antes de su destierro no era desconocido en Alemania. Así, el escritor Alfred Kerr, tras su visita a España en la primavera de 1923, escribía a Unamuno, lamentando no haber podido encontrarlo, pues según afirmaba, había tenido «l'espoir de vous parler —étant sûr que vous êtes quelque chose comme un cousin d'esprit», y pidiéndole que le enviara «quelques mots qui me donnent une idée de votre manière d'envisager l'Espagne d'aujourd'hui» ${ }^{4}$.

Pero sería a partir de su exilio en París cuando cobre mayor fama. En ello tuvo no poco que ver un artículo del poeta surrealista Yvan Goll, que se publicaría por primera vez el 31 de diciembre de 1924 en la Königsberger Hartungsche Handelszeitung, uno de los diarios en alemán más antiguos, siendo luego reproducido en Suiza, en la Neue Zürcher Zeitung y otros diarios alemanes. Goll cuenta cómo en el Café de la Rotonde, donde la «juventud cree, a base de cubismo, jazz y amor libre, poder conquistar el siglo», se había formado últimamente una «mesa española» presidida por Miguel de Unamuno, «uno de los más grandes poetas y novelistas de España, hoy un mártir nacional desterrado por la dictadura». Goll describe la animación con la que el escritor discute con sus compañeros de mesa, «muy animado, golpea la mesa, ríe como el más joven de los estudiantes» y se pregunta asombrado: «¿Es éste el rector de la universidad medieval de Salamanca? ¿Es éste el hombre venerado como vigoroso revolucionario que se enfrenta a los sables de un general?» Aunque Goll prefiere centrarse en las anécdotas de la vida de Unamuno en París, hace notar a sus lectores que «debe saberse que es hoy en día el filósofo más profundo de la raza española, deben conocerse sus obras, de las cuales muy pocas se han traducido al francés o al alemán» (Goll, 1924).

De un cariz algo distinto es el artículo del romanista Ernst Robert Curtius, que aparecería meses después en diarios alemanes como el Hannoversche Kurier y en el suizo Neue Zürcher Zeitung, y donde el prestigioso romanista, más que insistir sobre las circunstancias del destierro, pretende exponer algunas claves de los ensayos de quien consideraba «el mayor representante hoy en día del espíritu español», que aunque «fuertemente arraigado en su tradición, es un cosmopolita del mundo de las ideas, un europeo, aunque clame contra la "europeización" de España». Tras resumir brevemente el contenido de En torno al casticismo, pasaba a Del sentimiento trágico de la vida, cuya publicación era inminente, Curtius define el anhelo de inmortalidad como «el eje» en torno al cual gira la obra unamuniana, y lo que le otorgaba originalidad en una época en la que «forma parte del buen tono de la Europa intelectual no hablar de muerte o eternidad» (Curtius, 1925).

${ }^{4}$ Carta de Alfred Kerr, Burgos, 24-IV-1923. Casa-Museo Unamuno, Salamanca. Esta carta no se incluye en la recopilación realizada por Pedro Ribas y Fernando Hermida. 
También el Frankfurter Zeitung prestaría notable atención a Unamuno. Se daba la circunstancia de que, más de una década atrás, en 1914, su corresponsal en España había dedicado un feroz artículo a Unamuno en el que hablaba de «germanofobia» a propósito de sus críticas a unas palabras que el químico Wilhelm Ostwald dijera sobre España, y se presentaba al escritor vasco como alguien obsesionado por resultar «ingenioso» y resentido por no haber sido aún «tomado en serio» en los círculos cultivados de Madrid (Gold, 1914). Esos tiempos quedaban atrás, y en enero de 1928, la Frankfurter Zeitung publicaría en diez entregas consecutivas la traducción alemana de Cómo se hace una novela (Unamuno, 1928a) siempre en la primera página. Ello a pesar de que Fritz Schotthöfer, corresponsal en París, con motivo de la publicación de las novelas cortas recogidas en el tercer volumen de sus obras, había realizado una valoración no muy positiva de unas narraciones donde «tienen cabida casi todas las excentricidades mentales», que estarían «escritas magistralmente, pero al margen de la vida». Como sería frecuente en las críticas a Unamuno, se le achacaba a sus personajes un carácter «demasiado agudamente intelectual, pues están ahí sólo para desarrollar el problema en cuestión [...]. no son hombres de carne y sangre, sino pruebas» (Schotthöfer, 1926).

La obra de Unamuno fue referida con cierta frecuencia en el Berliner Tageblatt, que junto al diario de Frankfurt era el diario liberal más importante de la época. Así, Hermann Hesse saludaba la aparición en alemán de «las obras principales del español Unamuno [...] estas creaciones de un espíritu caballeresco: duras, llenas de fuerza, algo ásperas, algo misántropas pero a la vez tan magníficas y elegantes» (Hesse, 1926). Pero como era de esperar, al lector de prensa le interesaba más la fuerte personalidad del autor y el drama de su destierro. Incluso cuando se trata de dar cuenta de la aparición de una de sus obras esta se interpreta a partir de su carácter. Un escritor como Heinrich Mann no escapa a esta tónica y en su reseña de la traducción alemana de La tía Tula, describe de manera pintoresca su encuentro con Unamuno durante un banquete del Pen Club en París, en 1925, retratándolo físicamente en estos términos: «Su cabeza era esbelta [...]. Su nariz, aunque afilada, hacía pensar en un hombre culto, no en un aventurero. Tenía además de su barba blanca, cortada decorosamente, gafas; y detrás de ellas, sus ojos negros miraban fríamente, cuando no ensoñados. Hacía pensar en una tormenta sureña». Precisamente una tormenta es lo que describe Mann al referir la intervención de un acalorado Unamuno: «Un volcán, ni más ni menos. Se aferraba el pecho, como si fuera a desgarrárselo. ¡Qué voz ronca de pasión! Nadie necesitaba comprender una palabra, el tono lo decía todo [...]. Cuando terminó aplaudimos todos, lo cual era bastante inadecuado; pues para qué aplaudir cuando ha descargado una gran tormenta». Mann extrapola este carácter a sus libros, donde aparecen personajes aparentemente cotidianos y apacibles que de pronto estallan en una tormenta de pasiones ignoradas en el norte de Europa. En el caso de la tía Tula, es el ideal de pureza que, para Mann, hace algo extraordinario de «esta enemiga de 
la vida tan plena de ardiente vitalidad», con una mezcla de ridículo y sublime, que considera propia de lo español, de un país que «sigue siendo oscuro para nosotros» (Mann, 1927) y que identifica con Unamuno.

Meses después, el Berliner Tageblatt denunciaba la violenta reacción del gobierno de Primo de Rivera ante la mención de una posible candidatura de Miguel de Unamuno al Premio Nobel de Literatura, para la que consideraba «indigno» al escritor, proponiendo en su lugar a Concha Espina. En la breve noticia se comentaba con ironía que «la 'escritora' Concha Espina se ha dado a conocer en España por su fervorosa colaboración en La Nación, diario oficioso de Primo de Rivera. Hasta ahora nunca se pensó que semejantes prestaciones justificaran la aspiración al Premio Nobel que se quiere negar al incómodo y genial escritor» («Unamuno», 1928). Y cuando finalmente se produjera el regreso triunfal de Unamuno a España, el Berliner Tageblatt envió a un enviado especial a Salamanca, que describiría en primera página cómo la ciudad «recibió al Rector de su Universidad como hasta ahora sólo había recibido a los militares victoriosos [...] aplaudido por las mujeres en los balcones, rodeado por un júbilo inacabable», todo ello para «un humilde anciano, el vencedor espiritual en la amarga lucha con el poco cultivado dictador que hace seis años le enviara a la árida isla de Fuerteventura». Hans Theodor Joel recogería igualmente unas palabras de Unamuno contra el monarca Alfonso XIII y señalaba el fervor republicano que había presenciado en Irún (Joel, 1930).

Por su parte, en el Vossische Zeitung, el diario más antiguo de la capital berlinesa, y que dirigido por Georg Bernhard era un decidido apoyo de los partidos liberaldemócrata y socialista, se reseñaría la aparición en alemán de La tía Tula, que visiblemente conmovió al comentarista, que lo define como «un libro de una crueldad desmedida [...] un libro que nos solivianta, nos hace sufrir, incluso nos asquea - y a la vez nos cautiva, con su inmersión en inauditas honduras psicológicas», y que habría de comprenderse solo «teniendo en cuenta el espíritu o más bien la falta de espíritu del catolicismo» (C.M., 1927). El crítico dejaba sin embargo claro que el narrador no tomaba partido en ninguna manera contra la protagonista.

Poco después, Fritz Heinzius contaba en «Visita a Unamuno» el viaje que hizo a Hendaya para encontrar al «luchador por la verdad y la justicia, desterrado por Primo de Rivera» (Heinzius, 1928). Heinzius describe la vida cotidiana de Unamuno, que «diariamente recibe visitas» y elogia hiperbólicamente su sabiduría: «No hay nada que no conozca, en ninguna parcela de la literatura o la ciencia. Consume masas ingentes de libros, ingleses, franceses, alemanes, italianos, aparte de en las lengua antiguas». Heinzius prefirió hablar con Unamuno de autores alemanes como Scheler, Kleist o Heinrich Heine «cuyos poemas me cita de memoria», para tratar a continuación de sus proyectos, entre las cuales le habla de un desconocido «estudio sobre la 'psicología 
del verdugo'» $»^{5}$. Finalmente, Unamuno le habló de su deseo de viajar a Dinamarca, de la que le habían hablado los marineros de Hendaya.

A partir de su exilio, la «visita a Unamuno» se había convertido casi en un subgénero propio, y numerosos periodistas germanos hicieron la peregrinación a París primero y luego a Hendaya. Un buen ejemplo del patetismo y grandilocuencia con el que se describía el exilio del escritor vasco es la «Visita a Unamuno» de Albert H. Rausch, que se publicó en la liberal Kölnische Zeitung poco después del fin del exilio de Unamuno, y en la que su autor describe la visita que le hiciera un año antes. Rausch, que alcanzaría celebridad como novelista bajo el seudónimo de Henry Benrath, abría su artículo con una larga disquisición sobre cómo de joven, al leer las Tristia de Ovidio le impactó la crueldad de la pena del destierro, lo cual le hacía especial el viaje a Hendaya. Rausch describe sus dificultades para encontrar a Unamuno, al que localiza finalmente en una taberna jugando a las cartas. El autor se demora en describir los rasgos de Unamuno: «No le había visto antes, ni tampoco ninguna imagen suya. Pero era realmente como me lo había imaginado. Inusualmente serio, mucho dolor reflejado en el sencillo y hermoso rostro. Y cierto cansancio en los ojos». Rausch cuenta cómo Unamuno se dirigió a él: «¿No querrá hablar conmigo de política?, me preguntó él enseguida, algo desconfiado... "No hablo sobre mi país"». Rausch le tranquilizó al respecto, afirmando que «usted sabe que tiene muchos amigos en Alemania», y a continuación hablaron de este país, pues Unamuno «estaba familiarizado con los asuntos alemanes. Acababa de leer a Remarque», para finalmente dedicar la mayor parte de su conversación a la Antigüedad clásica. Al cruzar la frontera hacia España, Rausch cae en la cuenta «del dolor que implica el destierro», e imagina con patetismo la situación de Unamuno: «Día tras día, desde hace años, los ojos de este hombre atisbaban su patria más allá del Bidasoa... Día tras día tenía frente a sí la silueta de la hermosísima Fuenterrabía... y siempre debía permanecer inalcanzable» (Rausch, 1930).

La atención a la obra de Unamuno cubría todo el espectro político. Así, la Arbeiterzeitung [Gaceta de los trabajadores], órgano de la socialdemocracia austríaca, fundado en 1889 , le dedicaría un amplio comentario con ocasión de la reedición de sus obras por la vienesa Phaidon-Verlag, que se había hecho con sus derechos tras la quiebra de Meyer \& Jessen. En el artículo, aparecido apenas un año antes de que el austrofascismo del canciller Dollfuß pusiera fin al diario, el anónimo comentarista comparaba el papel que «el anciano filósofo poético» [Dichterphilosoph] desempeñaba en la conciencia espiritual de España con el de Gerhart Hauptmann en el ámbito germanoparlante, aunque destacaba la mayor carga filosófica y científica del escritor español, lo cual explica-

\footnotetext{
${ }^{5} \mathrm{Al}$ parecer era un proyecto sobre el que pensaba desde al menos dos años antes, según se infiere de la correspondencia con Heinrich Auerbach (Ribas y Hermida, 2002: 228).
} 
ba que no haya encontrado «un círculo de lectores demasiado amplio», algo probado por las «realmente escasas tiradas a las que se limitó la edición de sus obras principales Don Quijote y Sancho [sic] y La tía Tula». Tras resumir el contenido de estas obras y de la novela Abel Sánchez, el comentarista comparaba a Unamuno con un «investigador de la estratosfera que utiliza la bien asentada tierra sólo como lugar de despegue y aterrizaje» y terminaba reivindicando su posición política, recordando a los «celosos jaleadores de un nacionalismo adulterado» que «este poeta Miguel de Unamuno, apolítico, trascendental y católico, políticamente se sitúa a la izquierda» (O.K., 1933).

Como se ha mencionado, la quiebra de Meyer \& Jessen y el exilio de la Phaidon-Verlag harían que la obra de Unamuno dejara de ser accesible al público alemán. Pocos años después, su fallecimiento pasó mayormente desapercibido. En la Deutsche Allgemeine Zeitung se presentaría a Unamuno como alguien a quien no se podían perdonar errores pasados como su apoyo a «los enemigos de Alemania» durante la Primera Guerra Mundial, pero que supo «aprender de la realidad», asumir durante la República el «naufragio del liberalismo» que apoyara durante casi toda su vida y volverse «contra la anarquía y el intento de bolchevizar España, al ponerse del lado de los nacionalistas con palabras y hechos» («Miguel de Unamuno», 1937). El anónimo periodista nazi, que por supuesto callaba la oposición de Unamuno a los rebeldes en sus últimos meses de vida, lo presentaba como «un símbolo» de la renovación fascista española.

\section{UNA AMPLIA Y VARIOPINTA RECEPCIÓN. UNAMUNO EN LAS REVISTAS LITERARIAS}

La primera revista literaria que informó sobre Unamuno fue Die Neue Rundschau, fundada en 1890 y dirigida por el editor Samuel Fischer. La revista, de carácter liberal, fue un escaparate de la mejor literatura alemana. Apenas dos meses después del destierro de Unamuno, Willy Haas contaba, en un artículo titulado significativamente «De la cámara de los horrores», las circunstancias en que se produjo dicho destierro, sin ahorrar ironía hacia el «hinchado dictador» que expulsaba al «mayor filósofo de España y sin duda una de las mentes contemporáneas más valiosas» (1924: 411). Haas aprovechaba para resumir las líneas principales de El sentimiento trágico de la vida y la Vida de Don Quijote y Sancho, lamentando que el nombre de Unamuno fuera «conocido sólo de unos pocos» en Alemania (1924: 413). Die Neue Rundschau contribuyó a combatir esta ignorancia con la publicación, en abril de 1926, de un extracto de la segunda de las obras citadas, «El sepulcro de Don Quijote», seguido de un ensayo «Sobre Unamuno» a cargo de Ernst Robert Curtius, donde este pretendía explicar «qué significa este hombre [...] para España y para Europa» (1926b: 163), aunque se limite a estudiar la obra ensayística de 
Unamuno, repasando sus ideas sobre el «casticismo» y sus reparos frente al fervor europeísta de Ortega, sus críticas a la erudición filológica, su «quijotismo» y el sentimiento trágico, para finalmente calificarlo con un epíteto que se haría célebre, por ser «único por el dinamismo de su personalidad. Es el despertador de su nación. Es un Excitator Hispaniae, aguijoneando, exigiendo y vivificando» (1926b: 180). La fama de Curtius haría que el artículo se reprodujera «por su significación excepcional» en la revista bonaerense Nosotros, donde se resaltaba que no era sino una de las muchas «notas o referencias sobre Unamuno publicadas en Alemania a raíz de sus dificultades con el Directorio y de la publicación de sus traducciones» («Las revistas», 1926).

Die Neue Rundschau seguiría con atención la publicación de las obras de Unamuno y, con motivo de la aparición de Niebla, el escritor Paul Wiegler caracterizaba la novela como de «un trágico grotesco, de una agilidad de nuestros Tieck o Hoffman, que pone a prueba la candidez del lector» (1927: 429). Wiegler se mostraba impresionado por la oración fúnebre por modo de epílogo, que le parece de una «sombría pero sonriente soledad» y define como «el breviario de un pensador que, en la época después de Nietzsche, es demasiado valeroso como para necesitar la protección de las ilusiones» (1927: 430).

Willy Haas fundaría poco después, gracias al apoyo del editor Ernst Rowohlt, la revista quincenal Die literarische Welt, que alcanzaría la enorme tirada de 30.000 ejemplares y se caracterizaría por su vocación de actualidad. Esta se ponía de manifiesto en las frecuentes entrevistas y encuestas realizadas entre los escritores más célebres del momento. Así, la revista abrió sus dos primeros números con una encuesta que bajo la pregunta «¿Qué agradece usted al espíritu alemán?» recogía la respuesta de varios escritores europeos como Paul Valéry, Jean Cocteau, Ilya Ehrenburg, Paul Claudel o Miguel de Unamuno. Este había recibido pocos meses antes una carta de Paul Medina, corresponsal en París de Die literarische Welt, en la que este le aseguraba que «estaríamos felices si recibiéramos de su pluma, altamente estimada, una respuesta de una cincuentena de líneas si es posibles» ${ }^{6}$. La respuesta de Unamuno fue, con mucho, la más amplia de los encuestados. El escritor vasco comenzaba por declararse «bastante escéptico» sobre el concepto de espíritu de un pueblo (Volksgeist) y prefería hablar de lo que debía a la lengua alemana, recordando cómo con dieciséis años comenzó a estudiar alemán para poder leer a Hegel y elogiando la flexibilidad del alemán, que permite «la continuidad y el paso de un concepto a otro, ese desarrollo interior que permite que las ideas se conformen en pensamientos y permanezcan en el cauce de la lengua» (Unamuno, 1925a). Unos meses después, Curtius publicaba un breve ensayo sobre Unamuno, casi coetáneo al que publicara en Die Neue Rundschau, aunque

${ }^{6}$ Carta de Paul Medina, París, 9-V-1925. Casa-Museo Unamuno, Salamanca. La carta no ha sido publicada ni en la recopilación realizada por Pedro Ribas y Fernando Hermida ni en el epistolario editado por Colette y Jean-Claude Rabaté. La traducción es mía. 
con un tono más ligero e irónico sobre el dictador Primo de Rivera al que cabía agradecer «haber hecho visible a un guía espiritual de nuestro presente europeo». Curtius definía a Unamuno como «un tradicionalista revolucionario» y apuntaba que, si bien con motivo de su destierro se había convertido en un ídolo de los demócratas, sus ideas serían más bien conservadoras. De todos modos, resume Curtius, los asuntos que le importan a Unamuno son intemporales, ya que «Unamuno es eternista» (Curtius, 1926a: 6). Por entonces, Meyer \& Jessen había comenzado la publicación de las «obras reunidas» de Unamuno, de la cual serían reseñados dos volúmenes en Die literarische Welt. En el primer caso, Curtius, al reseñar la Vida de don Quijote y Sancho, y recordando el pasaje en que Sancho se encuentra con unos peregrinos alemanes, acusaba a sus compatriotas de dirigirse a España siempre con una conciencia de «superioridad técnica y económica» en lugar de «aprender algo» de un país que contaba con escritores como Unamuno, Ortega, Baroja, Azorín, Pérez de Ayala, Machado o Juan Ramón Jiménez (1926c). Un año después, el escritor expresionista austríaco Hermann Bahr mostraba su entusiasmo por Niebla, y calificaba el encuentro de Augusto Pérez y su creador como «una escena de una mezcla tan sublime entre broma grotesca y aniquilador sentimiento trágico, que no tiene parangón en la literatura contemporánea» (1927: 3). Bahr ya había hablado más por extenso de Unamuno en su ensayo «Noticias sobre la literatura española actual», publicado en los conservadores Preussische Jahrbücher y posteriormente en forma de libro, y donde calificaba al escritor vasco como «el más rico interiormente, el más conmovido de anhelos, el más implacable (también contra sí mismo) pensador de España» (1925: 139) y al que reconocía haber inventado, con sus soliloquios un «género en realidad totalmente nuevo» (1925: 147).

También en la revista berlinesa Die Horen, su director Hanns Martin Elster señalaría el descubrimiento de Unamuno como «un notable enriquecimiento de nuestro saber sobre la literatura mundial de nuestros días» y confesaría que su lectura fue para él «una profunda experiencia». Elster dedicaba su atención sobre todo a El sentimiento trágico de la vida, y destacaba que «muy pocas veces ha expresado un pueblo su deseo de inmortalidad, su intuición de la eternidad, de manera tan coherente, fuerte y moderna como el español a través de Unamuno». Sin embargo, Unamuno habría debido reconocer que el elemento motriz de su pasión religiosa provenía de Nietzsche: «Reconocer la vida en todo lo que tiene de trágico y a la vez afirmarla: Esto no es sino la filosofía y el heroísmo de Nietzsche» (Elster, 1927: 293)7.

Entre las grandes revistas berlinesas, Der Querschnitt, fundada en 1921 y dependiente de la gran casa editorial Ullstein, fue la que menor atención pres-

${ }^{7}$ Elster sería años después uno de los portavoces más entusiastas del régimen hitleriano, siendo redactor-jefe de la revista Das Dritte Reich y del diario Nationalsozialistische Beamtenzeitung. 
tó a Unamuno, algo explicable quizás por su espíritu lúdico, laico y elitista, en el que no encajaban demasiado las preocupaciones del escritor español. $\mathrm{Su}$ única aparición es una entrevista de Edda Reinhardt, que bajo el título «¡Unamuno como escultor!», se centra en la afición del escritor por la papiroflexia, que le resultaba más novedosa a esta periodista: «Miguel de Unamuno, el luchador por la libertad, el filósofo, el gran escritor: sus obras, ardientes de impulso apasionado, son conocidas en Alemania. Pero muy pocos saben que este espíritu fuerte y creativo en sus horas de ocio da forma a pequeñas obras maestras de la papiroflexia» (Reinhardt, 1928: 713) .

Con el objetivo de abarcar la actualidad literaria, pero con un diseño menos moderno y cosmopolita (con letra gótica y escasísimas ilustraciones) que el de las revistas berlinesas, se publicaba desde 1898 en Stuttgart la revista Die Literatur, subtitulada «Publicación mensual para amigos de la literatura». Dirigida por el crítico Ernst Heilborn, Die Literatur prestaría notable interés al devenir de Unamuno y sus obras. Así, en octubre de 1928 se publicó un personalísimo ensayo de Wilhelm Hausenstein, crítico de literatura y arte, especialista del Barroco, sobre Unamuno, de quien elogiaba su amplitud de intereses, que contraponía a la tendencia a la especialización que dominaba en Alemania y que consideraba empobrecedora: "Indiferente a la necesidad de preservar "la dignidad profesional de un filósofo" como por ejemplo Hegel, Unamuno se sienta a la misma mesa para escribir teología, novelas y relatos —él, a quien por otra parte nadie podría acusar de eclecticismo» (1928: 6). Para Hausenstein, las obras de Unamuno se dividirían «en dos grupos: Comentarios y obras épicas», aunque en realidad «las narraciones de Unamuno son también comentarios», por ejemplo La tía Tula sobre la «inmaculada concepción». Diciendo lo cual no pretendía desmerecerlas, pues para el crítico alemán, la más bella de las obras de Unamuno es su comentario a Don Quijote. Sin embargo, Hausenstein echa en falta en estas «novelas de pensamiento» la visualidad, lo pictórico que ve logrados al máximo en autores como Fiodor Dostoyevski o Knut Hamsun, y lamenta que por ejemplo apenas sepamos «qué aspecto tiene Augusto Pérez». En algunos momentos, opina, «sus novelas parecen como una exposición de tesis con notas a pie de página» pero finalmente siempre el temperamento del escritor «que piensa con el corazón» salva la ficción (1928: 7).

Menos interesante es la reseña que dedicaría Hans Roselieb a la traducción de Paz en la guerra, y que prácticamente se limita a ser un canto al pueblo vasco y su arraigo ancestral (1930: 424) ${ }^{9}$. En una fecha ya tardía como 1934,

${ }^{8}$ Un par de años después, el director de Der Querschnitt se dirigiría a Unamuno pidiéndole colaboración, pero sin obtener respuesta (Ribas y Hermida, 2002: 302).

9 Roselieb, dramaturgo expresionista, se adheriría con entusiasmo al nazismo, hasta el punto de quitarse la vida en abril de 1945 cuando vio entrar el ejército estadounidense en la localidad donde se había refugiado. 
apareció un ensayo sobre Unamuno a cargo del escritor Reinhold Schneider, que por aquel entonces se interesaba especialmente por la historia de Portugal y España ${ }^{10}$, y que tiene el interés de reseñar brevemente la aparición en de San Manuel Bueno, mártir, o de resaltar la importancia de los libros de viajes de Unamuno «que lamentablemente aún no han sido traducidos, aunque permiten, mejor que ninguna otra obra, acceder a la comprensión de España» (1934: 144). Igualmente tiene palabras de elogio para La tía Tula, donde Unamuno logra acceder a la esfera trágica que muchas veces gobierna la vida familiar, y denunciar la paradoja de «lo trágico de la moral que destruye la vida y a la vez la mantiene, y que sólo podía haber sido descubierto por el espíritu despierto de una raza [la española]». Y es que para Schneider, como para tantos otros críticos, «Unamuno es la encarnación del ser de España, con ese toque de lejanía o incluso aversión a la historia», de modo que con él se rompió el molde y en las generaciones más jóvenes «no se encuentra la sustancia española con la misma fuerza» que en Unamuno. Todo ello no significaba ningún tipo de tosco nacionalismo, pues el escritor vasco «no pierde nunca la vinculación con el conjunto de la vida europea ni se deja caer en el patrioterismo, un rancio destino que entretanto nos amenaza a los alemanes» (1934: 145), según concluía Schneider, con una velada crítica al nacionalsocialismo que estaba provocando el acelerado deterioro de la cultura en Alemania. En el mismo número de Die Literatur, en la sección de noticias, se informaba del homenaje que había recibido Unamuno en Salamanca con motivo de su septuagésimo cumpleaños, y durante el cual «en muchas calles los libreros improvisaron puestos donde vendían obras del homenajeado a precios populares» («Nachrichten», 1934).

Unamuno se convirtió en un escritor de referencia a nivel europeo, sobre el que toda revista cultural se veía obligada a tomar posición. No fue menos Die Tat, revista de política y cultura, fundada en 1909, en Jena, por el editor Eugen Diederichs y que llevaba por entonces el ambicioso subtítulo de «revista mensual para la formación de una nueva realidad». La publicación se convertiría en uno de los portavoces más exitosos de la revolución conservadora, pero en 1929 estaba siendo aún dirigida por el germanista Adam Kuckhoff, que precisamente sería despedido meses después por haber tratado de convertir la revista en un foro de pensamiento liberal y de izquierdas, lo cual chocaba con la posición derechista del editor. Es precisamente en este breve interregno progresista en el que aparece el ensayo «Miguel de Unamuno», de Otto Forst-Battaglia, escritor e historiador austríaco que, como se convertiría en un lugar común, comenzaba afirmando que Unamuno «encarna su pueblo, más que cualquier otro escritor de hoy a cualquier nación» (1929: 750). Forst-Battaglia

${ }^{10}$ Había publicado en 1930 un libro sobre el Imperio portugués (Das Leiden des Camoes) y en 1931 una biografía de Felipe II (Philip II oder Religion und Macht). 
habla primero de los ensayos de Unamuno sobre Don Quijote y sobre el sentimiento trágico y, frente a las críticas que otros autores alemanes habían vertido sobre el español por su asistematismo, él lo defiende como reflejo del carácter nacional español, «totalmente distinto al de fríos intelectuales como Maurras en Francia o Vaihinger en Alemania» ${ }^{11}$, pues mientras estos «encuentran en la vida la medida de todas las cosas, el español tiene constantemente la muerte frente a los ojos» (1929: 755). A continuación, Forst-Battaglia estudia las novelas de Unamuno como «casos aplicados de sus teorías filosóficas» y que según señala agudamente, no son «narraciones filosóficas, sino filosofía narrada». Contra los prejucios de algunos contra las novelas de tesis, el autor austríaco resalta «la forma de sus obras [...] las cualidades de un estilista extraordinario, de cegadoras antítesis y cristalina construcción de la frase»y menciona «un par de escenas que no tienen su igual en la literatura mundial: el grandioso acorde final de Abel Sánchez y la burlesca disputa del autor con su protagonista en la filosófica historia Niebla». Con todo, Forst-Battaglia compartía la opinión mayoritaria entre la crítica alemana, que consideraba que no sería «el narrador Unamuno, al que amamos y admiramos, el que perdurará en el lejano futuro», sino «el pensador original y poderoso» (1929: 756-757).

Y es que la obra de Unamuno fue comentada desde las revistas literarias más difundidas a las más minoritarias, como la divertida y unipersonal Der Zwiebelfisch [El alburno], subtitulada «revista sobre libros, arte y estilo de vida», fundada en Múnich, en 1909, y redactada íntegramente por Hans von Weber, director de la editorial Hyperion. Tras su muerte en 1924, su hijo Wolfgang von Weber tomó el relevo de la revista, y sería él quien reseñara la aparición de los tres primeros volúmenes de las obras reunidas de Unamuno, a quien elogia en sus dos facetas, tanto como «filósofo-poeta de rango único en Europa» como, sobre todo, en tanto que narrador, que «se adentra más audaz, apasionada y radicalmente en los abismos de lo psíquico que ningún otro contemporáneo, con un arte del diálogo excelsamente logrado». Weber resaltaba la originalidad de las «nivolas» de Unamuno, por las que podía «orgullecerse de ser el creador de un nuevo y acendrado concepto novelístico» (1926a). Dos meses después, Weber reseñaba la aparición de la Vida de Don Quijote y Sancho, que le confirmó en su entusiasta opinión sobre Unamuno: «Un libro extrañamente reflexivo. Un acontecimiento grandioso: sublime, magnífico, genial. Esta exégesis del clásico Don Quijote es una de las mayores revelaciones de la literatura europea [...]. Aquí se abre un modo de terapia espiritual, un espíritu gigantesco que resplandece desde cada línea. Sugestivo, cálido, profundo, abierto. Es un libro que cura» (1926b).

11 Como veremos, meses antes había aparecido en los Kant-Studien, revista dirigida por Hans Vaihinger, una reseña muy negativa de El sentimiento trágico de la vida. 
También en las revistas más académicas se prestaría atención a Unamuno. Poco después de que lo hiciera Curtius, otro de los romanistas germanos más respetados, Ludwig Pfandl, especialista en el Barroco español, había publicado en la Literaturblatt für germanische und romanische Philologie un comentario a los tres primeros tomos publicados de las obras reunidas. Comenzaba hablando del común rechazo hacia la dictadura primorriverista del escritor vasco y Vicente Blasco Ibáñez, los dos escritores más conocidos en Alemania, para a continuación señalar las diferencias pues Unamuno era «serio, honesto, abierto, directo y, a pesar del extremismo de sus opiniones, guarda siempre una elegante discrección» (1926: 112). Sobre todo, Pfandl resalta que «al contrario que Ibáñez, no es un germanófobo», como prueba de lo cual citaba las «sobrias palabras de amistad» que le había enviado Unamuno poco después de la derrota en la Gran Guerra, y que Pfandl transcribe: «Sé en qué soledad y desnudez viven ustedes los intelectuales alemanes, y lo deploro mucho. Espero que este trágico estado de cosas acorte pronto y se recomponga la hermandad de la civilización humana» ${ }^{12}$. Como otros críticos, Pfandl distinguía entre el hombre, el narrador y el ensayista, aunque al contrario que otras voces, consideraba a este último como inferior, y decía «venerarlo como hombre, tenerlo en alta estima como narrador pero, como ensayista filosófico, cuando se trata de ciertas concepciones del mundo, lo rechazo categóricamente». Asimismo, el romanista bávaro anunciaba que estaba prevista la traducción de sus «bellas Andanzas y visiones españolas, en las que el escritor, a lo largo y ancho de la península, hace que su paisaje, arte y costumbres cobren vida gracias a su personalísimo estilo caviloso, excéntrico, pero siempre atractivo», proyecto que finalmente no se llevó a cabo (1926: 114).

También las revistas berlinesas de izquierdas, de carácter literario y político, hablarían de Unamuno. Lo haría muy pronto Die Weltbühne, revista semanal de política, arte y economía, fundada en 1905, y en la que sería uno de sus redactores más destacados, Kurt Tucholsky, quien bajo el seudónimo de «Ignaz Wrobel» quien describiría el exilio de Unamuno, aprovechando para criticar la falta de reacción de los socialdemócratas alemanes a la injusticia cometida por el dictador español (Wrobel, 1924).

Otra revista muy similar, aunque de carácter mensual, era Das Tage-Buch, dirigida por el sociólogo Leopold Schwarzschild. En esta aparecería una reseña de Niebla, a cargo de Oscar Maurus Fontana, escritor expresionista que mostró gran entusiasmo por la obra, declarando: «Aquí está la novela del siglo XX, escrita por un hombre del siglo XX. Nuestra exigencia de que en el nuevo escritor deben unirse la más alta fuerza de pensamiento con la forma literaria más elevada, ha sido satisfecha por Unamuno [...] en este español

12 En castellano y en cursiva en el original. 
cobran forma por primera vez nuestras intuiciones y deseos sobre el nuevo tipo de escritor» (1926: 1942).

Pero a pesar del compromiso de Unamuno contra la dictadura, entre las publicaciones de izquierdas no todas las reseñas serían positivas. Las ambigüedades del pensamiento unamuniano o su preocupación por el destino del individuo eran propensas a suscitar la incomprensión, cuando no la ira, de los autores comprometidos totalmente con alguna ideología de transformación social. Así se entiende el cariz del artículo que, bajo el título «Don Quijote en el exilio», le dedicó Richard Gabel en Die Neue Bücherschau [El nuevo panorama de libros], revista mensual que dirigía en Múnich Gerhart Pohl, y que se situaba a la extrema izquierda, contando con muchos colaboradores miembros del Partido Comunista Alemán, como Johannes R. Becher, Bruno Frei o F. C. Weiskopf, entre los más conocidos. Para Gabel, miembro del consejo de redacción de Die Neue Bücherschau, toda preocupación por lo religioso se identifica con una posición reaccionaria, y así, su artículo abunda en amalgamas que habrían rebelado a Unamuno, afirmando que este, en su lucha por la fe, «aporta con celo jesuítico pruebas que no lo son, y habla como un arrojado adepto de Savonarola» (1929: 494). Para Gabel, resultaban anacrónicas estas preocupaciones y afirmaba que «se le escapa a su cerebro aprisionado religiosamente que el cielo se ha apagado definitivamente en el desarrollo de la conciencia de las masas» y que el memento mori de Unamuno «no seduce a ninguna mente moderna». Más que reseñar el contenido de las obras de Unamuno, Gabel prefiere mencionar sus carencias, por ejemplo señalando que «a Unamuno, encerrado en un laberinto de normas religiosas y éticas, se le escapa la relación entre trabajo y salario. Le falta el conocimiento de las relaciones de causa y efecto [...]. Su obstinación religiosa hace "aquí abajo" imposible la solución de los problemas sociales». Por ello, «la enconada lucha de Unamuno por la eterna duración del yo» es calificada como «un intento de huida encubierta de sí mismo, sin salida, engañoso», que solo podría redimirse al adherirse a la clase obrera en su lucha "con el valor de la desesperación, sin esperanza en Dios, con la fe en su objetivo, con la victoria como idea más alta [...]. Este es el único camino que conduce desde la soledad de la locura y lo trágico hacia el hombre, hacia la victoria final de la verdad». Esta lucha, para Gabel, sería además la del verdadero «quijotismo [...] la lucha contra cada injusticia, llevada a cabo con todas las consecuencias» (1929: 496).

Tampoco entre la extrema derecha nacionalista sería Unamuno bien recibido, como muestra la reseña de El sentimiento trágico de la vida aparecida en la Europäische Revue, publicación mensual fundada en 1925 por el Príncipe de Rohan, y que apostaba por un conservadurismo autoritario, que no ocultaba sus simpatías por los regímenes de Mussolini y de Primo de Rivera. La crítica sería escrita por el filósofo Paul Ludwig Landsberg, que por entonces compartía ideas de la revolución conservadora, y para quien la lucha unamuniana entre razón y sentimiento era algo superado por su generación: «La situación 
de Unamuno ya no es la nuestra. No nos hemos quedado atascados en sus contradicciones, sino que hemos intentado ver [...] dónde el conocimiento tiene sus límites necesarios. Para nosotros la fé no se opone a la razón, sino que le sirve como guía» (1926: 66). Pero Landsberg no seguiría siempre en esas certezas y cuando Hitler tomó al poder se exiliaría en Barcelona, releyendo desde otra óptica a Unamuno, que le interesaría desde su propio existencialismo cristiano y sobre el que en 1935 escribiría en muy otro tono sus conocidas «Reflexiones sobre Unamuno» para Cruz y Raya ${ }^{13}$.

También hablaría de Unamuno en una revista como Freie Welt [Mundo libre], «revista quincenal de cultura alemana», y que se editaba en la ciudad checoslovaca fronteriza de Jablonec nad Nisou, de población mayoritariamente germana, el crítico Ernst Viktor Zenker, nacionalista alemán que apoyaba la anexión de los Sudetes, y cuyas teorías raciales se traslucían en su ensayo sobre Unamuno cuando resaltaba la importancia que tendría su ancestral sangre vasca en la regeneración de la «agotada» cultura española, dando de paso muestras de notable ignorancia sobre la cultura española, al aportar como prueba el hecho de que tanto «Ignacio de Loyola como Don Quijote» [sic] fueran vascos (Zenker, 1926: 8). En el ensayo de Zenker se muestra esa retórica de la autenticidad que aparece en otras críticas positivas de Unamuno, mezclada siempre con el intento de aproximación a la cultura alemana por parte del crítico. Así, Zenker afirma que Unamuno «entra en una relación inmediata con el más verdadero ser», y con la galofobia propia de los nacionalistas alemanes reivindica que la filosofía de Unamuno tiene más recorrido que la de Bergson y además «se arraiga en el mundo de ideas alemán» (1926: 10). Zenker reconoce que Unamuno «no es un filósofo profesional, una falta que quizás sea reprochable a ojos de ese gremio, pero que a mí me lo hace más cercano». A continuación pasa a analizar cómo su filosofía de lo trágico se refleja en sus novelas, sobre todo en Abel Sánchez, donde Zenker, de manera algo apresurada, ve la polaridad de razón y sentimiento reflejada respectivamente en Joaquín Monegro y Abel Sánchez, y califica la novela como «de lo mejor que nos ha ofrecido la literatura contemporánea». Pero el crítico advierte que «no ha de creerse que Unamuno sea un escritor de programa, que deliberadamente da forma literaria a ideas filosóficas. Eso sería desconocer absolutamente el ser de Unamuno» (1926: 15).

También entre las revistas literarias situadas más a la derecha recibiría Unamuno críticas deliberadamente destructivas, demostrándose que nuestro autor suscitaba en Alemania pasiones encontradas. En pocos lugares como en la revista Die schöne Literatur, publicada en Leipzig y dirigida por el novelis-

${ }_{13} \mathrm{Al}$ estallar la guerra civil, Landsberg se exilió en París. Apresado por la Gestapo en 1943, moriría en el campo de concentración de Sachsenhausen en 1944. 
ta Will Vesper ${ }^{14}$, recibirían juicios tan arbitrarios las obras de Unamuno. El encargado de reseñar sus obras para esta revista de orientación nacionalista y que acogía a gran parte de los futuros publicistas del Tercer Reich, sería el joven germanista Wolfgang von Einsiedel, que con apenas veintitrés años no tendría reparos en descalificar, por tres veces, la obra del profesor de Salamanca. En la primera de las ocasiones, con motivo de la publicación de los tres primeros volúmenes de las obras reunidas de Unamuno, Von Einsiedel comienza ironizando sobre que «la coyuntura para la importación de escritores extranjeros parece propicia en estos momentos: después de Pirandello, ahora nos llega el español Unamuno. Entre ellos hay cierto parentesco: los dos [...] carecen de originalidad como pensadores y como escritores no pasan de hábiles constructores» (1926: 163). El joven germanista aborda primero la filosofía de Unamuno, que considera «apenas un guisado de citas y lugares comunes». Frente a los elogios que le tributaban otras plumas, Von Einsiedel declara con cierta petulancia que «como pensador apenas tiene algo que decirnos» y que «su capacidad de comprensión apenas le llega para Kierkegaard», por lo que «valor europeo, como se viene diciendo, no puede atribuírsele en modo alguno». Tampoco salvaba sus novelas, que no le parecían otra cosa que «esqueletos de alambre» o «historietas de calendario». Sobre Abel Sánchez, que había tenido un respetable éxito de ventas y público, opinaba que muestra una «psicología tan primitiva y grosera, como si su autor hubiera vivido doscientos años antes de Shakespeare» (1926: 164). Dos años después, Von Einsiedel volvió a ocuparse de Unamuno con motivo de la publicación de La tía Tula, y empezaba afirmando que la aparición de esa novela no había cambiado en lo esencial su primera impresión de Unamuno como carente de interés tanto como pensador como en tanto que novelista. Von Einsiedel reconoce lo fascinante del «conflicto entre instinto maternal y miedo al pecado en una fuerte personalidad femenina», pero opina que Unamuno no ahondó en el conflicto, «se quedó atascado en los preliminares» y finalmente lo solucionó «de manera sumamente primitiva en duelos verbales afilados dialécticamente, y exponiéndonos sus conclusiones, en lugar de mostrarlas mediante el desarrollo de la acción» (1928a). Y apenas seis meses después, con insistencia digna de mejor causa, Von Einsiedel reseñaba La agonía del cristianismo, con la misma acritud, comenzando por declarar que «cada libro de Unamuno es una nueva decepción» y le resultaba «cada vez más incomprensible, cómo este español, seguramente simpático como persona, ha llegado a gozar de una reputación europea como filósofo». Para Von Einsiedel no era sino un ejemplar de una especie que creía ya superada, la del «impresionista filosófico». Sobre la caracterización del cristianismo como lucha interior, opinaba que «podría aplicarse a cualquier otra

14 Vesper, de ideología nacionalista, apoyaría decididamente el nacionalsocialismo y su revista, bajo el nuevo título de Die Neue Literatur, se convertiría en la revista literaria más importante durante el régimen nazi. 
religión» y que aunque el libro contenga «algunos comentarios valiosos (especialmente sobre Pascal), ello no compensa la insignificancia del conjunto» (1928b).

\section{ENTRE EL INTERÉS Y EL RECHAZO DEFENSIVO. LA RECEPCIÓN EN LAS REVISTAS FILOSÓFICAS Y RELIGIOSAS}

El carácter trascendental del ensayo El sentimiento trágico de la vida suscitó amplio interés por el libro en el ámbito filosófico, hasta el punto de que pocos meses después de su aparición, la revista Philosophie und Leben [Filosofía y vida], dirigida por el filósofo y pedagogo August Messer, dedicaba un número monográfico a la cuestión de la inmortalidad. El propio Messer era el encargado de atacar a ese nuevo «campeón de la inmortalidad, que gracias a lo inquebrantable e ingenuo de su fé y al ímpetu de su oratoria, cuando no convencer, desde luego sabe cómo llamar la atención». Messer cita la confesión de Unamuno de que «no quiero morirme, no; no quiero, ni quiero quererlo; quiero vivir siempre, siempre, siempre, y vivir yo, este pobre yo que me soy y me siento ser ahora y aquí», y comenta con malicia que «esta pobre confesión es en su ingenuidad de agradecer y psicológicamente interesante, pero nos tememos que la realidad se preocupará poco de esta voluntad de vivir, incluso de un Unamuno» (1926: 278). Entrando en las tesis principales del libro, Messer dice tener la impresión de que Unamuno no sufre realmente con el sentimiento trágico, sino que «su lucha por creer en la inmortalidad es para él un “deporte", se le escapa su más honda gravedad» (1926: 274-275). La virulencia del ataque de Messer parece deberse a su rechazo a aceptar, como afirma Unamuno, que la creencia en la supervivencia del alma tras la muerte sea incompatible con la razón, para lo cual, incluso, llega a mencionar las «pruebas empíricas» que podría aportar el espiritismo. En opinión de Messer, en el pensamiento de Unamuno aparecían «rasgos sustanciales de un filosofar irracional que se ha vuelto moda en el presente», y que se caracterizaría por un «espíritu de violencia [...] que podemos observar tanto en el régimen bolchevique como en las dictaduras de las tres penínsulas sureñas». Y aquí venía el golpe más bajo del profesor de Giessen, cuando igualaba, con simplificación malintencionada, las críticas a la razón de Unamuno, con la represión de Primo de Rivera sobre el propio autor: «Unamuno 'argumenta' contra Kant y los idealistas, burlándose de ellos y ultrajándolos; Primo de Rivera 'argumenta' contra Unamuno, desterrándolo en una isla solitaria. La forma es distinta, pero el fondo es idéntico: ¡Despreciad a la razón y la ciencia!» (1926: 279) Sin duda, motejar a Unamuno de violento y enemigo de la razón solo podía obedecer a una lectura apresurada y a una reacción desmedida para contrarrestar la atención que había suscitado. 
También la revista Individualität, «revista bimensual para filosofía y arte», prestó especial atención al escritor vasco, reclamando su colaboración para un número monográfico sobre la reencarnación, que Unamuno satisfizo con su ensayo «Inmortalidad e individualidad», subtitulado «una guía para meditar durante el domingo de resurrección» (1927a). En el número siguiente de Individualität apareció la traducción de «tres sonetos filosóficos», entre ellos la célebre «oración del ateo» (1927b).

El sentimiento trágico también sería reseñado en los Kant-Studien [Estudios kantianos], revista cuatrimestral editada por la Sociedad Kant, dirigida por el conocido filósofo Hans Vaihinger. No extraña la atención prestada en esta revista a un libro donde se comenzaba por poner, como ejemplo de la oposición entre razón y sentimiento, el «salto mortal» del filósofo de Koenigsberg al escribir la Crítica de la razón práctica, donde se oponía al «hombre Kant» y «el profesor de filosofía» y donde se insistía en que «el idealismo crítico de Kant es de origen religioso». La reseña que le dedica Kurt Krippendorf, que comienza por señalar la erudición «asombrosa» de Unamuno, se caracteriza por un tono condescendiente, y en ella se trasluce el rechazo habitual por parte del establecimiento filosófico alemán ante pensadores que no siguen la tradición alemana de filosofía como sistema, y por ello comienza calificando a Unamuno entre «aquel solemne grupo de filósofos de la vivencia, cuya filosofía es menos ciencia que poesía y tiene que ver más con experiencia del mundo que con aprehensión intelectual» (1928: 440). Krippendorf elogia el estilo del escritor bilbaíno, y cita la máxima unamuniana de «obrar de modo que merezcas a tu propio juicio y al de los demás la eternidad», calificándola como «palabras doradas» que sin embargo «no son el fruto de un claro desarrollo lógico, sino que surgen esporádicamente» (1928: 443). La crítica más dura se dedica al concepto unamuniano de lo trágico, que para Krippendorf no ha sido «depurado de sus adherencias folletinescas de manera filosóficamente satisfactoria» y lamenta que haya renunciado a «fijar unívocamente sus conceptos», lo que era desconocer la manera de pensar de Unamuno. Para el crítico alemán, la consideración de lo trágico como la polaridad entre razón y sentimiento resultaba empobrecedora y con cierto chauvinismo contrapone «la consideración de nuestros grandes pensadores y poetas de lo trágico como destrucción de los valores [...] frente a la cual palidece la visión del mundo de Unamuno». Finalmente, Krippendorf acude al fácil recurso de igualar el pensamiento de Unamuno con la «mentalidad española», que se caracterizaría por su «conciencia católica» y su reivindicación del «dualismo de una Edad Media contradictoria y brillante» (1928: 444). Con ello, la reseña de Krippendorf caía en un fácil reduccionismo que condenaba a la incomprensión de los pensadores que no partieran de paradigmas filosóficos establecidos en Alemania ${ }^{15}$.

15 Kurt Krippendorf, profesor en un instituto berlinés, sufrió una radicalización derechista que le fue recompensada tras la llegada de Hitler al poder con su nombramiento en 
También en Logos, una «revista internacional de filosofía de la cultura» se hablaría de Unamuno. El encargado de hacerlo sería el romanista Victor Klemperer, que alcanzaría celebridad tras la Segunda Guerra Mundial con su brillante estudio sobre la lengua del Tercer Reich. Frente a la habitual comparación entre Pirandello y Unamuno, Klemperer resalta las diferencias entre ambos, que según él tienen su fundamento en que frente a la indiferencia religiosa del italiano, Unamuno «busca su más alta identidad en Dios, y esta ardiente religiosidad junto a la necesidad ética que conlleva da a sus ahondamientos psicológicos una profundidad irresistible y, en novelas como la españolísima Tía Tula o Abel Sánchez, nos sumerge hasta el fondo de las catacumbas del alma» (1929: 410).

En el ámbito de las revistas religiosas suscitó notable interés la publicación en alemán de La agonía del cristianismo, que sería comentada en las publicaciones protestantes y católicas, de modo siempre controvertido. En Christliche Welt, la revista protestante más prestigiosa y difundida en Alemania, fundada en 1888 por Martin Rade, teólogo liberal y demócrata, habría división de opiniones. La primera reseña, del latinista Hildebrecht Hommel es mayormente positiva, elogiando la originalidad de un «libro tan voluntarioso y a la vez tan humilde [...] un libro singular que nos hace vislumbrar, en el espejo de un profundo espíritu, la grandeza de una religión inmortal». Aunque Hommel confesaba no sentirse atraído por el estilo unamuniano, por sus aforismos o «antítesis y sutiles contradicciones», elogiaba a cambio el desarrollo conceptual del libro y en especial algún «pasaje magistral, cuando hacia el final del libro desarrolla de manera convincente, gracias al ejemplo del gran pensador cristiano Pascal, su tesis de la tensión y contradicción en la vida que fluye de Dios» (Hommel, 1929).

Meses después sería Georg Hellmuth Neuendorff, un pedagogo de llamativa trayectoria ${ }^{16}$, el encargado de hablar de la obra de Unamuno. Neuendorff comenzaba atacando la imagen que, a causa de su oposición a la dictadura, se había granjeado Unamuno entre los medios alemanes de izquierda, y afirmaba que «Unamuno no es ni un librepensador [...] ni un revolucionario internacional. Es justamente lo contrario: un español nacionalmente apasionado y cristiano católico convencido» (1930: 538). Entrando a valorar sus ideas, Neuendorff compara a Unamuno con Spengler, pues las obras de ambos estarían caracterizadas por un mismo carácter rimbombante, y sentencia: «Hay autores que muestran objetivos, ofrecen soluciones, transmiten conocimientos superio-

1933 como presidente de la Comisión evaluadora para Historia y Geografía encargada de la censura de los libros de estas materias.

16 Neuendorff había huido a Argentina en 1920 tras descubrirse los abusos que ejercía en la escuela que dirigía. Tras ser detenido, fue condenado a seis años de prisión. Después de cumplir su condena volvió a colaborar en la prensa cultural, mostrando un creciente interés por la literatura hispanoamericana. 
res. Entre ellos no se cuentan ni Spengler ni Unamuno». Para Neuendorff, más allá del sentido de «aventura» que le transmite la obra unamuniana, y a pesar de que Unamuno mereciera «nuestra compasión humana» por su destierro, «no cabe esperar ninguna respuesta en sus obras a las cuestiones sociales que agitan el mundo del presente» (1930: 539). El pedagogo prusiano aprovecha para repasar brevemente la trayectoria de Unamuno como narrador y llama la atención sobre la importancia de sus artículos de prensa, que había conocido durante su época de prófugo en Argentina. Sin embargo, tampoco en su narrativa podían esperarse «soluciones satisfactorias» para las vitales cuestiones que planteaba, concluyendo con sarcasmo: «Hay que tener en cuenta que Unamuno es sobre todo el autor del libro sobre El sentido trágico de la vida. Parece entonces evidente, no insistir más en respuestas: la vida es siempre nueva, siempre diferente y siempre trágica» (1930: 540).

En cuanto a las revistas culturales católicas, que vivían una época dorada, seguramente la de mayor nivel fue la publicación mensual Hochland [Meseta], editada en Múnich, fundada en 1903 por Carl Muth, representante del existencialismo católico y que agrupó en torno a sí a lo más granado de la intelectualidad católica liberal. Muth propugnaba la regeneración espiritual de Alemania tras la derrota en la Gran Guerra, y su revista prestó atención temprana a la obra de Unamuno. Ya en 1926, Eberhard Vogel le dedicó un largo ensayo aparecido en dos entregas. Vogel, que residió durante varias etapas de su vida en España y sería autor de un exitoso diccionario español-alemán, era tres años mayor que el escritor vasco. Su artículo tiene una finalidad divulgativa y se centra casi exclusivamente en la obra ensayística de Unamuno, lo que se explica por la sorprendente opinión del alemán de que «con sus novelas Unamuno se ha perjudicado a sí mismo. Sus personajes son esquemas sin carne» (1926: 231). Mientras que la primera parte del ensayo se centra en su trayectoria biográfica y en Andanzas y visiones españolas, en la segunda comienza Vogel por lamentarse, como otros críticos alemanes, de la falta de sistematicidad de Unamuno y pretende enmendarlo en cierto modo pues, dado que lo que el autor vasco expresara sobre el pueblo y la cultura españoles «está tan desperdigado a lo largo de sus escritos que es realmente laborioso reunirlos en algunos puntos de vista homogéneos, trataré exponer sus pensamientos con cierto orden» (1926: 214). Para ello, Vogel cita extensamente de los ensayos unamunianos, sobre todo de El sentimiento trágico, traducida al alemán el año antes, y con cuyas ideas principales simpatiza.

Unos años después, con motivo de la traducción al alemán de La agonía del cristianismo, Otto Knapp hablaba de ella en la sección sobre «vida y fé de este tiempo» que dirigía en Hochland. Curiosamente, Knapp, que pocos años después publicaría una exitosa biografía de Santa Teresa de Jesús, reseñaba el libro de Unamuno justo después de hablar de la traducción alemana de El tema de nuestro tiempo de Ortega y Gasset, para enlazar, sin mucha lógica, las predicciones sobre la nueva época de Ortega con su convicción de que «el hombre 
de mañana será cristiano» y que la «primavera cristiana» estaba llegando, de manera conflictiva, para las almas más inquietas, de las cuales sería muestra excelsa la obra de Unamuno, a la que define como «un libro de convulsiones», propio de un alma «extrañamente inquieta, en búsqueda, anhelante, desgarrada y sin paz», cuyas dudas se exacerbarían «hasta lo patológico», por lo que resulta «un libro que le crispa a uno los nervios» (1931: 175). El estilo de Unamuno, sin duda, desconcertaba a gran parte de los lectores alemanes, que no valoraban especialmente las paradojas. Para Knapp, «si despojamos a las ideas de Unamuno de sus ensortijados accesorios de ocurrencias e ingeniosidades, se nos revelan como antiguas o incluso antiquísimas conocidas», a pesar de lo cual asegura que la obra «es un libro personalísimo, el libro de un hombre al que la España conservadora condenó a un durísimo destierro», y a quien Knapp considera de «la estirpe de Pablo, Agustín y Pascal, todos ellos luchadores de la fe, que tuvieron que luchar con su Dios». El principal mérito de la obra de Unamuno sería, para Knapp, recordar que «sólo con la lógica, aunque sea la lógica de la pasión, no puede penetrarse en la esencia del cristianismo. Quien no conoce la lengua del amor, no pasará de ser un mineral exclamativo o una tintineante campanilla» (1931: 176). La obra de Unamuno, por tanto, venía a confirmar para Knapp su interpretación de que «el nuevo sentimiento vital de nuestro tiempo siente hacia el cristianismo una relación nueva, más cercana y más profunda» (1931: 180).

En la misma ciudad de Múnich se editaba otra importante revista católica, aunque de orientación política muy distinta. Los Süddeutsche Monatshefte [Cuadernos mensuales del Sur de Alemania], fundados en 1904 por Paul Nikolaus Cossman, habían funcionado hasta la Primera Guerra Mundial como órgano de un catolicismo liberal que reivindicaba la particularidad de Baviera. Tras la derrota, sin embargo, Cossman derivó rápidamente hacia un nacionalismo conservador y revanchista, dando cada vez más espacio en su revista a los representantes de la revolución conservadora. Uno de los más conspicuos, Edgar J. Jung, sería el encargado de reseñar La agonía del cristianismo ${ }^{17}$. Jung señalaría cómo se sintió atraído desde el principio por el concepto de agonía entendida como «lucha» y reconoce que le costó esfuerzo juzgar objetivamente esa obra, pues «a los alemanes nos une con ese español, lo que une a Don Quijote con Fausto» (1928: 631). Jung elogia las críticas de Unamuno a una época, en la que «la creencia en los milagros de la fe ha sido sustituida por la

17 Jung, líder de un grupo de combate de extrema derecha, había estado implicado en el asesinato del presidente del Palatinado en 1924 y alcanzó notable fama con la publicación de Die Herrschaft der Minderwertigen [El reinado de los inferiores] (1926), una violenta diatriba contra la democracia, el liberalismo y el parlamentarismo, de la que curiosamente se le ofreció a Unamuno hacer una reseña, algo que este declinó (Ribas y Hermida, 2002: 125). Víctima de la violencia que él mismo propagara, Jung sería asesinado el 30 de junio de 1934, en las purgas de la Noche de los cuchillos largos. 
creencia en los milagros de la ciencia», pero finalmente, al tratar sobre la que para él resulta la cuestión fundamental de la obra, la consideración del cristianismo como individualismo radical, se niega a aceptar dicha tesis, pues para Jung, «la religión es un concepto de vida en común» y «lo que Unamuno llama el más íntimo ser del cristianismo no es sino eterno protestantismo» (1928: 633). Con todo, Jung afirma que Unamuno es más consecuente que Nietzsche y que, al contrario que este, obra para resolver el gran dilema entre fe y comunidad que, para el publicista alemán, resultaba la cuestión decisiva del siglo XX.

Pero las críticas más duras vendrían a Unamuno desde otra revista católica, Der Gral [El Grial], subtitulada «revista mensual de literatura» ${ }^{18}$, que dependía del Gralbund [Unión del Grial], asociación de escritores conservadores y católicos, fundada en Viena en 1905. Der Gral, editada en la ciudad bávara de Ratisbona, era dirigida por el padre jesuita Friedrich Muckermann, quien sería precisamente el encargado de pronunciarse sobre La agonía del cristianismo, obra que descalifica desde el principio como «una de las mezclas más indigestas de misticismo y dialéctica» que ha tenido que digerir. Por ello no entiende la fama de Unamuno, salvo que «sean el acientifismo, la falta de lógica, la falta de originalidad, el misticismo confuso de cabo a rabo, las características que hoy en día aseguran la celebridad» (1927: 759). Respecto al tema de la obra en cuestión, Muckermann lo reduce a «la cuestión de la relación entre cristianismo y cultura moderna», que considera un lugar común, aunque en Unamuno había surgido de un "sufrimiento que le da una alta seriedad, una urgencia espiritual», apiadándose de la cual, el padre jesuita renuncia a «abordar los muchos errores de esta obra [...], las numerosas simplificaciones, las verdades a medias, los juicios históricos erróneos, que hallamos casi en cada página» (1927: 761). Abordando ya las tesis principales del libro, Muckermann afirma que el carácter alemán siente «especialmente cercano el sentimiento trágico de este español», pero desprecia la rebeldía de Unamuno ante la muerte: «Lo que más nos separa de él, es que nosotros no constatamos llorosamente esta agonía ni la hacemos resonar en una constante jeremíada de la existencia, sino que la reconocemos gozosamente, porque sabemos que en ella se basa la vida». Frente al proclamado renacimiento intelectual católico, Muckermann percibe lo contrario, «una falta de autenticidad, de realidad, de fuerza, en la literatura católica» y la ve porque «falta esa sangre, que siempre debe verterse, si el hombre quiere alcanzar un nivel superior. Falta esa marcha hacia la puerta de la muerte, desde la cual únicamente se avista el porvenir de la vida» ${ }^{19}$. Especialmente le repugna al padre jesuita la angustiosa pregunta que cierra el

18 Cambiaría este subtítulo pocos años después por el de «revista católica de literatura $\mathrm{y}$ vida».

19 Llama la atención por parte de Friedrich Muckermann esta apología del sacrificio, que compartiría con los grupos nacionalistas. Sin embargo, Muckermann se opondría vigo- 
ensayo de Unamuno, y le replica que «Cristo no nos ha abandonado, sino que le han abandonado los que no quieren comprender que para ser un discípulo de Cristo hay que llevar su cruz, día por día. Las culturas que olvidan esto mueren, no la muerte para la vida, sino la muerte para la putrefacción» (1927: 762-763).

No era de extrañar, de todos modos, la acritud de un jesuita hacia quien había calificado en esa obra a los miembros de su orden como «los degenerados hijos de Íñigo de Loyola» (Unamuno, 1962: 84), y esta se repetiría tres años antes, cuando con motivo de su regreso del exilio, su nombre volviera a estar en todos los medios y Hubert Becher, igualmente sacerdote jesuita quisiera aclarar a los lectores de Der Gral la verdadera importancia de Miguel de Unamuno. Para Becher, se estaba dispensando «mucho incienso, demasiada pleitesía al retornado o mejor dicho a [...] la política en cuyo símbolo se ha convertido el nombre de Unamuno. Y es uno de los descubrimientos más turbadores, ver cuantas verdades a medias y voluntades partidistas se vierten sobre el gran angustiado» (1930: 1017). De manera similar a Muckermann, Becher rechazaba el pensamiento de Unamuno al que reprochaba no entregarse, «no perder su alma para ganarla», por lo que a su juicio habría «en su fogoso espíritu algo de mezquino y enconado, por lo que sufre pero que no logra superar», careciendo de la «libertad interior hacia la que tiembla cada fibra de su ser, y seguirá mezclando lo raro, satírico, irónico, deforme y condenatorio en los himnos de sus anhelos»». Al igual que tantos otros, Becher reiteraba que el hombre Unamuno contaba «con la simpatía que no podemos otorgar a sus libros»y, es más, consideraba estos no ya inútiles sino nocivos para la solución de los problemas del país que representaba, pues «Unamuno desgarra aún más las contradicciones de España, en lugar de curarlas y la vida espiritual sigue infructuosa». Sin embargo, para Becher, en el extranjero se sobrevaloraba la influencia del profesor salmantino que, se da a entender, se debía a su afán de protagonismo: «Resulta falso hablar sólo de unamunistas y antiunamunistas en España. Hay también eruditos, poetas, líderes populares, que trabajan en silencio. Su obra crece lentamente, pero a ellos pertenece el futuro» (1930: 1018).

\section{LA RECEPCIÓN EN OTROS TIPOS DE REVISTAS}

La fama de Unamuno hizo que sus obras se convirtieran en lectura obligada para cualquier persona que quisiera estar à la page de lo más novedoso en la literatura europea y así, sus obras son comentadas en la sección de crítica incluso de revistas de medicina o tiempo libre. Por ejemplo, en la revista Archiv

rosamente al nazismo y tendría que exiliarse a partir de 1934 en Holanda y posteriormente en Suiza. 
für Frauenkunde und Konstitutionsforschung, publicada en Wurzburgo y fundada en 1914 por Max Hirsch, uno de los pioneros de la ginecología moderna, aparece una breve reseña, escrita por el propio Hirsch, sobre la aparición en alemán de Abel Sánchez, El espejo de la muerte, El sentimiento trágico de la vida y Niebla, donde el célebre médico califica a Unamuno como «no sólo el mayor filósofo y la figura más significativa del espíritu español [...] sino que puede considerársele sin temor como uno de los mayores representantes de la cultura europea» (Hirsch, 1927). El autor se asombra de que Unamuno parezca «conocer casi todas las literaturas y filosofías del mundo» y como narrador elogia su «profundo conocimiento de la psicología y valoración del dominante problema de los sexos», que le hacen compararlo con Dostoyevski, aunque se distingue de él por la mayor «contundencia, brevedad y concentración de su expresión». El doctor berlinés llega a prever que gracias a Unamuno el «espíritu de España» comience a superar al de Francia o Italia.

También en los Neue Jahrbücher für Wissenschaft und Jugendbildung, la pedagoga Helene Lingelbach, en un artículo sobre la creación literaria como medio de producción de significado para la vida, citaba en su apoyo al Unamuno de Cómo se hace una novela (1929: 596). Y Erik-Ernst Schwabach, en la Internationale Zeitschrift für Individualpsychologie, también citaba como autoridad a Unamuno para criticar las pretensiones absolutistas del psicoanálisis frente a otras tendencias psicológicas (Schwabach, 1927: 349).

El nombre de Unamuno aparece en las revistas más inesperadas, como en Die Freude [La alegría], subtitulada «cuadernos mensuales para una libre conformación de la vida» y que no era sino una publicación del ámbito naturista, editada en Egestorf, ciudad pionera en los baños nudistas. Hans Harbeck se lamentaba de que «la gran masa de los lectores» (1928) aún no conociera las obras de Unamuno, pero su mera mención en una revista como esta es buen ejemplo de la amplitud que tuvo la difusión de este escritor durante aquellos años.

\section{CONClusión}

El cotejo exhaustivo de una larga serie de publicaciones nos ha demostrado que la recepción de Unamuno en Alemania durante los años veinte e inicio de los treinta fue mucho más amplia y variada de lo que hasta ahora se había creído y, si no se alargó más en el tiempo fue, por una parte, debido a la quiebra y el exilio de las editoriales que habían publicado sus obras en Alemania y Austria y, por otra, al empobrecimiento generalizado de la cultura bajo la dominación hitleriana. Asimismo, si fue el destierro de Unamuno lo que primero llamó la atención de los lectores alemanes, su fama no puede reducirse, ni mucho menos, a las anécdotas sensacionalistas de su exilio. Ya antes de la publicación de sus «obras reunidas», romanistas como Ernst Robert Curtius o 
Ludwig Pfandl se habían interesado por su obra. La traducción de sus novelas y ensayos más conocidos harán que Unamuno sea, durante este período, el escritor español más conocido, incluso más que Ortega y Gasset, a quien, hasta la traducción de La rebelión de las masas, superaba en la amplitud de su recepción.

Respecto a los modos de recepción de los distintos grupos del riquísimo campo literario de la República de Weimar, cada vez más politizado, hemos podido comprobar que Unamuno fue rechazado con virulencia por quienes apoyaban ideologías totalitarias, tanto comunistas como nacionalistas de derechas, profascistas y partidarios de la revolución conservadora. Asimismo, suscitaría el rechazo de quienes percibían su pensamiento como un intrusismo, ya fuera en los campos de la filosofía o del pensamiento religioso. Desde este punto de vista se explican tanto las críticas que recibió por el órgano más importante de la filosofía kantiana o por los jesuitas de la conservadora Der Gral.

En cambio, sería acogido con gran interés, por una parte, por escritores de vanguardia, especialmente expresionistas (como atestiguan los elogios de Hauptmann, Heine, Hesse, Bahr o Fontana) que valoraban sus innovaciones narrativas, sobre todo en Niebla y Abel Sánchez; por otra, por quienes, reacios a sostener ningún dogma unívocamente, sintieron como suyas las preocupaciones existenciales de Unamuno, o quienes saludaban, como letraheridos deseosos de novedades, la originalidad de aquel sorprendente escritor español. En cualquier caso, Unamuno, que nunca puso el pie sobre el suelo de Alemania, despertó en ese país admiraciones y rechazos apasionados. Sobre la dimensión de su influencia, oculta por la llegada del nazismo y su posterior olvido, queda aún no poco por investigar.

\section{FUENTES PRIMARIAS}

Bahr, Hermann (1925). «Notizen zur neueren spanischen Literatur», Preussische Jahrbücher. CC, 1 (abril), pp. 13-22 y CC, 2 (mayo), pp. 136-167.

Bahr, Hermann (1927). «Zu Unamunos Roman Nebel», Die literarische Welt. III, 51 (23 diciembre), p. 3.

Becher, Hubert (1930). «Miguel de Unamuno», Der Gral. Monatsschrift für schöne Literatur. IX, 2, pp. 1016-1018.

C.M. (1927). «Unamunos Tante Tula», Vossische Zeitung. 20 de noviembre.

Curtius, Ernst Robert (1925). «Unamuno oder die Philosophie des Tragischen», Hannoversche Kurier. 4 de octubre. Reproducido en: Neue Zürcher Zeitung. 8 de octubre.

Curtius, Ernst Robert (1926a).«Unamuno», Die literarische Welt. II, 4 (22 enero), pp. 6-7.

Curtius, Ernst Robert (1926b).«Über Unamuno», Die Neue Rundschau. XXXVII, 2 (febrero), pp. 163-181.

Curtius, Ernst Robert (1926c). «Sancho Panza und die Pilger», Die literarische Welt. II, 21-22 (21 mayo), p. 5 
Einsiedel, Wolfgang von (1926). «Unamuno, Miguel de. Gesammelte Werke. Das tragische Lebensgefühl. Der Siegel des Todes. Abel Sánchez», Die schöne Literatur. XXVII, 4, pp. 163-164.

Einsiedel, Wolfgang von (1928a). «Unamuno, Miguel de. Tante Tula», Die schöne Literatur. XXIX, 2 (febrero), p. 89.

Einsiedel, Wolfgang von (1928b). «Unamuno, Miguel de. Die Agonie des Christentums», Die schöne Literatur. XXIX, 8 (agosto), p. 398.

Elster, Hans Martin (1927). «Bücherschau. Gesamtausgaben», Die Horen. III, pp. 291-295.

Fontana, Oscar Maurus (1926). «Miguel de Unamuno: Nebel», Das Tage-Buch. VII, 51 (18 diciembre), pp. 1942-1943.

Forst-Battaglia, Otto (1929). «Miguel de Unamuno», Die Tat. Monatschrift zur Gestaltung neuer Wirklichkeit. XX, 10 (enero 1929), pp. 750-757.

Gabel, Richard (1929). «Don Quichotte im Exil. Über den fünfundsechzigjährigen Unamuno», Die Neue Bücherschau. VII, 8 (agosto), pp. 494-496.

Gold, L. (1914). «Herr Miguel de Unamuno. Germanophobes aus Salamanka [sic]», Frankfurter Zeitung. 4 de abril.

Goll, Ywan (1924). «Miguel de Unamuno», Königsberger Hartungsche Handelszeitung. 31 de diciembre. Reproducido en: Neue Zürcher Zeitung, 5 de enero de 1925 y Dresdner Neueste Nachrichten, 18 de enero de 1925.

Haas, Willy (1924). «Aus der Schreckenkammer», Die Neue Rundschau. XXXV, 4 (abril), pp. 411-414.

Harbeck, Hans (1928). «Unamuno. Die Freude», Monatshefte für freie Lebensgestaltung. II, 5 (febrero), p. 91.

Hausenstein, Wilhelm (1928). «Unamuno», Die Literatur. Monatschrift für Literaturfreunde. Vol. XXXI, 1 (octubre), pp. 3-8.

Heinzius, Fritz (1928). «Besuch bei Unamuno», Vossische Zeitung. 5 de enero.

Hesse, Hermann (1926). «Reisegedanken», Berliner Tageblatt. 7-8 de octubre.

Hirsch, Max (1927). «Miguel de Unamuno. Abel Sanchez. Der Spiegel des Todes. Das tragische Lebensgefühl. Nebel», Archiv für Frauenkunde und Konstitutionsforschung. XIII, p. 198.

Hommel, Hildebrecht (1929). «Unamuno. Die Agonie des Christentums», Die christliche Welt. XLIV, 8, p. 592.

Joel, Hans Theodor (1930). «Gespräch mit Unamuno», Berliner Tageblatt. 15 de febrero.

Jung, Edgar Julius (1928). «Die Agonie des Christentums. Zu den neuen Buch Unamunos», Süddeutsche Monatshefte. XXV, 9, pp. 631-633.

Knapp, Otto (1931). «Vom Leben und Glauben dieser Zeit», Hochland. XXVIII, 8 (mayo) pp. 173-180.

Landsberg, Paul Ludwig (1926). «Miguel de Unamuno tragisches Lebensgefühl», Europäische Revue. II, 1 (abril), pp. 65-66.

«Las revistas. Unamuno en Alemania. Un estudio de Curtius» (1926), Nosotros. LIV (20 de noviembre), pp. 415-416.

Mann, Heinrich (1927). «Unamuno», Berliner Tageblatt. 1 de octubre.

Messer, August (1926). «Unamuno über die Unsterblichkeit», Philosophie und Leben. II, 8 (agosto), pp. 274-279.

«Miguel de Unamuno» (1937), Deutsche Allgemeine Zeitung. 2 de enero.

Muckermann, Friedrich (1927). «Dichtung und Leben», Der Gral. Monatsschrift für schöne Literatur. VI, 22, pp. 759-763.

«Nachrichten» (1934), Die Literatur. XXXVII, 3 (diciembre), p. 180. 
Neuendorff, Georg Hellmuth (1930). «Miguel de Unamuno», Die christliche Welt. XLV, 11, pp. 537-540.

O.K. (1933). «Bedeutsame Neuausgaben», Arbeiterzeitung. 1 de abril.

Pfandl, Ludwig (1926). «Miguel de Unamuno. Gesammelte Werke», Literaturblatt für germanische und romanische Philologie. XLVII, 3-4 (marzo-abril), pp. 112-114.

Rausch, Albert H. (1930). «Besuch bei Unamuno», Kölnische Zeitung. 12 de febrero.

Reinhardt, Edda (1928). «Unamuno als Bildhauer!», Der Querschnitt. VIII, 10 (octubre), pp. 713-714.

Roselieb, Hans (1930). «Frieden im Krieg», Die Literatur. XXXII, 7 (abril), p. 424.

Schneider, Reinhold (1934). «Unamuno», Die Literatur. XXXVII, 3 (diciembre), pp. 141145 .

Schotthöfer, Fritz (1926). «Unamuno, Der Spiegel des Todes», Frankfurter Zeitung. 10 de septiembre.

Unamuno, Miguel de (1925a) «Fortsetzung unserer Rundfrage. Was verdanken Sie dem geutschen Geist», Die literarische Welt. I, 2 (16 de octubre), p. 2.

Unamuno, Miguel de (1927a). «Unsterblichkeit und Individualität. Ein Leitfaden zu Meditationen für das Auferstehungsfest», Individualität. Zweimonatschrift für Philosophie und Kunst. II, 1-2, pp. 41-47.

Unamuno, Miguel de (1927b). «Drei philosophische Sonette», Individualität. Zweimonatschrift für Philosophie und Kunst. II, 3, pp. 112-114.

Unamuno, Miguel de (1928a). «Wie ein Roman entsteht», Frankfurter Zeitung. 13 al 22 de enero.

«Unamuno des Nobelpresis 'unwürdig'?» (1928), Berliner Tageblatt. 1 de noviembre.

Vogel, Eberhard (1926). «Miguel de Unamuno. Ein spanischer Publizist und Philosoph», Hochland. XXIII, 7 (abril), pp. 20-31 y XXIII, 8 (mayo), pp. 214-231.

Weber, Wolfgang von (1926a). «Unamuno. Der Spiegel des Todes», Der Zwiebelfisch. Zeitschrift über Bücher, Kunst und Lebensstil. XIX, 1, p. 39.

Weber, Wolfgang von (1926b). «Unamuno. Don Quijote und Sancho», Der Zwiebelfisch. Zeitschrift über Bücher, Kunst und Lebensstil. XIX, 3-4, p. 130.

Wiegler, Paul (1927). «West-Östliche Romane», Die Neue Rundschau. XXXVIII, 4 (abril), pp. 426-433.

Wrobel, Ignaz [Kurt Tucholsky] (1924). «Unamuno spricht», Die Weltbühne (30 octubre).

Zenker, Ernst Viktor (1926). «Don Miguel de Unamuno», Freie Welt. 145, pp. 7-16.

\section{BIBLIOGRAFÍA CITADA}

Bourdieu, Pierre (1992). Les règles de l'art. Genèse et structure du champ littéraite. Paris: Seuil.

Hauptmann, Gerhart (1980). Diarium 1917 bis 1933. Frankfurt: Propyläen-Verlag.

King, Shirley (2000). «The Fame of Miguel de Unamuno in Germany. Its Growth and Decline, 1924-1930», en Conrad Kent (ed.), The Lion and the Eagle. Interdisciplinary Essays on German-Spanish Relations. New York: Berghahn, pp. 290-310.

Klemperer, Victor (1929). «Weltliteratur und europäische Literatur», Logos. Internationale Zeitschrift für Philosophie der Kultur. XVIII, pp. 362-418.

Krippendorf, Kurt (1928). «Unamuno, Miguel de. Das tragische Lebensgefühl», Kant-Studien. XXXIII, pp. 440-442. 
Lingelbach, Helene (1929). «Kunstkritische Wandlungen. Besonders über Dichtung als Lebensdeutung», Neue Jahrbücher für Wissenschaft und Jugendbildung. V, 5, pp. 589596.

Marcuse, Ludwig (1981). Meine Geschichte der Philosophie. Frankfurt/Main: Diogenes.

Niedermayer, Franz (1964). «Unamuno und Deutschland. Zum 100. Geburtstag Miguel de Unamunos am 29. September 1964», Literaturwissenschaftliches Jahrbuch. V, pp. 177200.

Ribas, Pedro y Hermida, Fernando (2002). Unamuno. Cartas de Alemania. Madrid: Fondo de Cultura Económica.

Schwabach, Erik-Ernst (1927). «Psychoanalyse und Individualsychologie. Versuch eines Nachweises ihrer Antagonien», Internationale Zeitschrift für Individualpsychologie. Arbeiten aus dem Gebiete der Psychotherapie, Psychologie und Pädagogik. V, pp. 348351.

Unamuno, Miguel de (1925b). Das tragische Lebensgefühl. Gesammelte Werke, vol. I. Robert Friese [Paul Adler] (trad.); Ernst Robert Curtius (intr.). München: Meyer \& Jessen.

Unamuno, Miguel de (1925c). Abel Sanchez. Die Geschichte einer Leidenschaft. Gesammelte Werke, vol. II. Walther von Wartburg (trad. y pról.). München: Meyer \& Jessen.

Unamuno, Miguel de (1925d). Der Spiegel des Todes. Novellen. Gesammelte Werke, vol. III. Otto Buek y Oswald Jahns (trad.). München: Meyer \& Jessen.

Unamuno, Miguel de (1926a). Das Leben Don Quijotes und Sanchos. Erster Teil. Gesammelte Werke, vol. IV. Otto Buek (trad. e intr.). München: Meyer \& Jessen.

Unamuno, Miguel de (1926b). Das Leben Don Quijotes und Sanchos. Zweiter Teil. Gesammelte Werke, vol. V. Otto Buek (trad.). München: Meyer \& Jessen.

Unamuno, Miguel de (1927c). Nebel. Gesammelte Werke, vol. VI. Otto Buek (trad.). München: Meyer \& Jessen.

Unamuno, Miguel de (1928b). Tante Tula. Gesammelte Werke, vol. VII. Otto Buek (trad.). München: Meyer \& Jessen.

Unamuno, Miguel de (1928c). Die Agonie des Christentums. Gesammelte Werke, vol. VIII. Otto Buek (trad.). München: Meyer \& Jessen.

Unamuno, Miguel de (1929). Frieden im Krieg. Ein Roman aus de Carlistenaufstand. Otto Buek (trad. y epílogo). Berlin: Volksverband der Bücherfreunde / Wegweiser-Verlag.

Unamuno, Miguel de (1930). Die Höhle des Schweigens. Otto Buek (trad. y epílogo). Leipzig: Reclam.

Unamuno, Miguel de (1933). Tante Tula. Ein Frauenroman. Abel Sánchez Die Geschichte einer Leidenschaft. Wien: Phaidon-Verlag.

Unamuno, Miguel de (1962). La agonía del cristianismo. Madrid: Espasa-Calpe.

Unamuno, Miguel de (2012). Cartas del destierro. Colette y Jean-Claude Rabaté (ed.). Salamanca: Ediciones Universidad de Salamanca.

Fecha de recepción: 7 de octubre de 2014.

Fecha de aceptación: 12 de marzo de 2015. 